\title{
Toxicity of Amorphigenin from the Seeds of Amorpha fruticosa against the Larvae of Culex pipiens pallens (Diptera: Culicidae)
}

\author{
Yaping Liang ${ }^{1}$, Xiuwei Li ${ }^{1, *}$, Zumin Gu ${ }^{1}$, Peiwen Qin ${ }^{1}$ and Mingshan Ji ${ }^{1,2, *}$ \\ 1 Department of Pesticide Science, College of Plant Protection, Shenyang Agricultural University, \\ Shenyang 110866, China; E-Mails: lypnancy628@163.com (Y.L.); guzumin1212@163.com (Z.G.); \\ qinpeiwen08@sina.com (P.Q.) \\ 2 Biopesticide Engineering Research Center of Liaoning Province, Shenyang 110866, China \\ * Authors to whom correspondence should be addressed; E-Mails: xiuwei001@syau.edu.cn (X.L.); \\ jimingshan@syau.edu.cn (M.J.); Tel.: +86-24-8834-2018 (X.L.); +86-24-8848-7148 (M.J.); \\ Fax: +86-24-8848-7148 (X.L. \& M.J.).
}

Academic Editor: Derek J. McPhee

Received: 16 December 2014 / Accepted: 10 February 2015 / Published: 16 February 2015

\begin{abstract}
The larvicidal activity of the crude petroleum ether, ethyl acetate, acetone, chloroform and ethanol extracts of Amorpha fruticosa seeds was individually assayed for toxicity against the early fourth-instar larva of the mosquito, Culex pipiens pallens after $24 \mathrm{~h}$ exposure. Of the tested extracts, the ethanol one exhibited the highest larvicidal activity $\left(\mathrm{LC}_{50}=22.69 \mathrm{mg} / \mathrm{L}\right)$. Amorphigenin (8'-hydroxyrotenone), a rotenoid compound which exhibits a strong larvicidal activity with $\mathrm{LC}_{50}$ and $\mathrm{LC}_{90}$ values of 4.29 and $11.27 \mathrm{mg} / \mathrm{L}$, respectively, was isolated from the ethanol extract by column chromatograpy. Its structure was elucidated by ${ }^{1} \mathrm{H}-\mathrm{NMR}$, UV and IR spectral data. Furthermore, investigation of amorphigenin's effects on mitochondrial complex I activity and protein synthesis in C. pipiens pallens larvae reveals that amorphigenin decreases mitochondrial complex I activities to $65.73 \%$ at $10.45 \mu \mathrm{mol} / \mathrm{L}$, compared to the control, when NADH were used as the substrate. Meanwhile, amorphigenin at $10.45 \mu \mathrm{mol} / \mathrm{L}$ also caused a 1.98 -fold decrease in protein content, compared to the control larvae treated with acetone only.
\end{abstract}

Keywords: Amorpha fruticosa; larvicidal activity; Culex pipiens pallens; amorphigenin; mitochondrial complex I; protein synthesis 


\section{Introduction}

Mosquitoes are significant public health pests due to their predominance as agents of potentially deadly pathogens in human beings and the annoyance of skin reactions caused by their bites [1]. Culex pipiens pallens Coquillett 1998, is the most common domestic mosquito species in Northern China, Korea and Japan, and is the primary vector of wuchereriasis, epidemic encephalitis B [2] and a potential vector of West Nile virus [3]. Since the 1950s, mosquito control strategies have depended primarily on the use of synthetic chemical insecticides [4,5]. However, repeated and injudicious application of synthetic insecticides has often resulted in the development of resistance to organochlorine, organophosphate, carbamate and pyrethroid insecticides [6-9]. Hence, in mosquito control, there is a constant need for developing alternatives to chemical insecticides. Natural, bio-active botanical compounds are a promising alternative for mosquito control because of lower toxicity to non-target organisms and their innate biodegradation ability [10,11].

In recent years, many studies on plant-borne compounds (e.g., essential oils and plant extracts) against a wide range of mosquito larvae have been conducted around the world [12]. Some novel mosquito larvicidal compounds were isolated and identified, and their modes of action have been investigated [13-17]. Among botanicals tested against mosquito larvae of Aedes aegypti, Aedes togoi and $C$. pipiens pallens are the following: methanol extracts from Cinnamomum cassia bark, Illicium verum fruit, Piper nigrum fruit, Zanthoxylum piperitum fruit, and Kaempferia galangal rhizome [18]; isobutylamides in Piper nigrum fruits [19]; active constituent isolate from Tabebuia avellanedae bark [20] and lignans in Phryma leptostachya var. asiatica root [21]. Compounds that subsequently demonstrated toxicity against larvae of Aedes aegypti and C. pipiens pallens include methanol extracts from Kigelia pinnata and Ruta chalepensis [22]; imperatorin and osthole from Cnidium monnieri fruit [23]; extracts from Cassia obtusifolia, Cassia tora and Vicia tetrasperma [24] and the chloroform fraction of Cassia obtusifolia extract and the biologically active component emodin [25].

The essential oil extracted from Coriandrum sativum fruits [26], Hyptis suaveolens [27], plus wild and cultivated Ruta chalepensis [28] were evaluated for larvicidal and repellent activities against the most invasive mosquito worldwide, Aedes albopictus. As well, Salvia dorisiana, S. longifolia and S. sclarea essential oils [29] were studied for repellent activity against $A$. albopictus. Neem seed oil [30], neem cake [31] of Azadirachta indica and their fractions were evaluated for larvicidal toxicity and field oviposition deterrence against $A$. albopictus. Furhtermore, essential oils extracted from Zingiber officinalis rhizome and leaf, plus the stem of Achyranthes aspera were evaluated for larvicidal, attractant/repellent, and oviposition attractant/deterrent activity against two mosquito species, Aedes aegypti and Culex quinquefasciatus [32]. The bioactivity of 14 essential oils from Cinnamomum osmophleum, Taiwania cryptomerioides, Cunninghamia lanceolata, Cryptomeria japonica and Calocedrus formosana were tested using the Aedes aegypti larvicidal assay [33]. Larvicidal activity of five medicinal plants, Abutilon indicum, Aegle marmelos, Euphorbia thymifolia, Jatropha gossypifolia and Solanum torvum were assayed for their toxicity against Culex quinquefasciatus [34]. The active compound (Z)-ligustilide of the chloroform extract from Angelica sinensis roots deterred the biting of two mosquito species, Aedes aegypti and Anopheles stephensis, more effectively than DEET [35]. 
As for insecticidal activity against mosquito larvae of $C$. pipiens pallens, the essential oils extracted from Amyris balsamifera, Daucus carota, and Pogostemon cablin were investigated [36]; Also evaluated were the crude methanol extract of Chamaecyparis obtusa leaves, its active component beta-thujaplicin [37] and four sesquiterpene alkaloids from an ethanol extract of Tripterygium wilfordii (Celastraceae) root bark [38]. Whole-plant crude petroleum ether, ethyl acetate, and methanol extracts of Phryma leptostachya have been tested for larvicidal activity against the early fourth-instar larvae of C. pipiens pallens, from which three lignans, phrymarolin-I, haedoxane A, and haedoxane E, were isolated and identified as new mosquito larvicidal compounds [39]. Extracts from seven species of bamboo were evaluated for larvicidal activity against $C$. pipiens pallens. Among these seven, extracts from Pleioblastus juxianensis, Brachystachyum albostriatum, Phyllostachys platyglossa and Pleioblastus amarus were found to be effective, with $\mathrm{LC}_{50}$ values at $24 \mathrm{~h}$ of $30.65 \mathrm{mg} / \mathrm{L}, 53.94 \mathrm{mg} / \mathrm{L}$, $41.21 \mathrm{mg} / \mathrm{L}$ and $54.49 \mathrm{mg} / \mathrm{L}$, respectively [40]. A methanol extract of Piper longum fruit was found to be active against mosquito larvae of $C$. pipiens pallens at $10 \mathrm{mg} / \mathrm{mL}$ after $24 \mathrm{~h}$, in which the piperidine alkaloid, pipernonaline, is the active principle, with an $\mathrm{LC}_{50}$ of $0.21 \mathrm{mg} / \mathrm{L}$ [41]. Ethanolic extracts from the Ginkgo biloba L. exocarp [42], ethyl cinnamate and ethyl p-methoxy-cinnamate from Kaempferia galangal rhizome [43], plus (-)-asarinin, $\alpha$-asarone, methyleugenol, pellitorine, and pentadecane from Asarum heterotropoides root [44] were all assayed against larvae of $C$. pipiens pallens. Using a direct-contact mortality bioassay, the toxicity of pellitorine alone, or in combination with (-)-asarinin, $\alpha$-asarone, and methyleugenol, or pentadecane was evaluated on third instars from an insecticide-susceptible KS-CP strain and a resistant DJ-CP colony of $C$. pipiens pallens [45].

Amorpha fruticosa is a perennial deciduous shrub in the Leguminosae family [46], introduced into China around the 1920s and widely planted throughout China for erosion control and to restore wasteland. Its fresh fruits were used for the treatment of carbuncles, eczema and burns [47]. Earlier research in the 1940s showed that extracts of A. fruticosa possess repellent and insecticidal activity against various insect species $[48,49]$. The acetone extract of $A$. fruticosa seeds was proved to be more toxic against $A$. aegypti larvae than $1 \%$ pure rotenone [49]. In our recent research [50], we found that ethanol extract from the seeds of $A$. fruticosa have good contact effects and anti-feedent activity against Schizaphis graminum. In the present study, our main target concentrated on larvicidal activity assessment of extracts and the isolated compound amorphigenin from the seeds of Amorpha fruticosa against early fourth-instar larvae of $C$. pipiens pallens. Moreover, expected effects of amorphigenin on mitochondrial complex I activity and protein synthesis of $C$. pipiens pallens were investigated to confirm its mode of action. Results from this study are expected to provide insights into mosquito larvicidal activity of seeds of Amorpha fruticosa and potential inhibition of amorphigenin against mitochondrial complex I and protein synthesis of $C$. pipiens pallens.

\section{Results and Discussion}

\subsection{Structural Elucidation of Amorphigenin}

The sample obtained from preparative high performance liquid chromatography was recrystallized from hot methanol to yield a sample of creamy white needles, which showed a single spot on thin-layer chromatography (TLC) over silica gel $(R f=0.45)$ with benzene/methanol $(9: 1)$ as the 
developing system, and a single HPLC peak (Figure 1). This compound possesses following physical properties: a melting point of $183{ }^{\circ} \mathrm{C}, \mathrm{UV}(\mathrm{MeOH}) \lambda \max =205,237$ and $294.1 \mathrm{~nm}$ (Figure 2) and an obvious $\mathrm{OH}$-stretching band at 3500 to $3400 \mathrm{~cm}^{-1}$ in its IR spectrum ( $\mathrm{KBr}$ disk, Figure 3), while other bands were similar to those of rotenone. ${ }^{1} \mathrm{H}-\mathrm{NMR}\left(\delta, \mathrm{CDCl}_{3}, 600 \mathrm{MHz}\right)=6.75(1 \mathrm{H}, \mathrm{s}, \mathrm{H}-1), 6.46(1 \mathrm{H}$, s, H-4), 4.19 (1H each, dd, $J=12.6$ and 2.4, H-6) 4.63 (1H each, dd, $J=12.6$ and 3, H-6), 4.94 (1H, m, H-6a), 6.52 (1H, d, $J=8.4, \mathrm{H}-10), 7.85(1 \mathrm{H}, \mathrm{d}, J=8.4, \mathrm{H}-11), 3.09$ (1H each, dd, $J=15.6$ and 8.4, H-4'), 3.45 (1H each, dd, $J=15.6$ and 9.6, H-4'), 5.44 (1H, t, $\left.J=7.8, \mathrm{H}-5{ }^{\prime}\right), 5.29$ (1H, s (br), H-7'), 4.27 (1H, s (br), H-8'), 3.76 and 3.85 (both $3 \mathrm{H}, \mathrm{s}, \mathrm{OMe}), 1.43$ (1H, s(br), 8'-OH), see Supplementary Material (Figure S1 ${ }^{1} \mathrm{H}-\mathrm{NMR}$ spectrum of amorphigenin). According to the similarity of spectral data to that reported by Sariaslani et al. [51] and Abe et al. [52], the abovementioned data, suggest that the obtained compound was identical to the known rotenoid, amorphigenin (Figure 4).

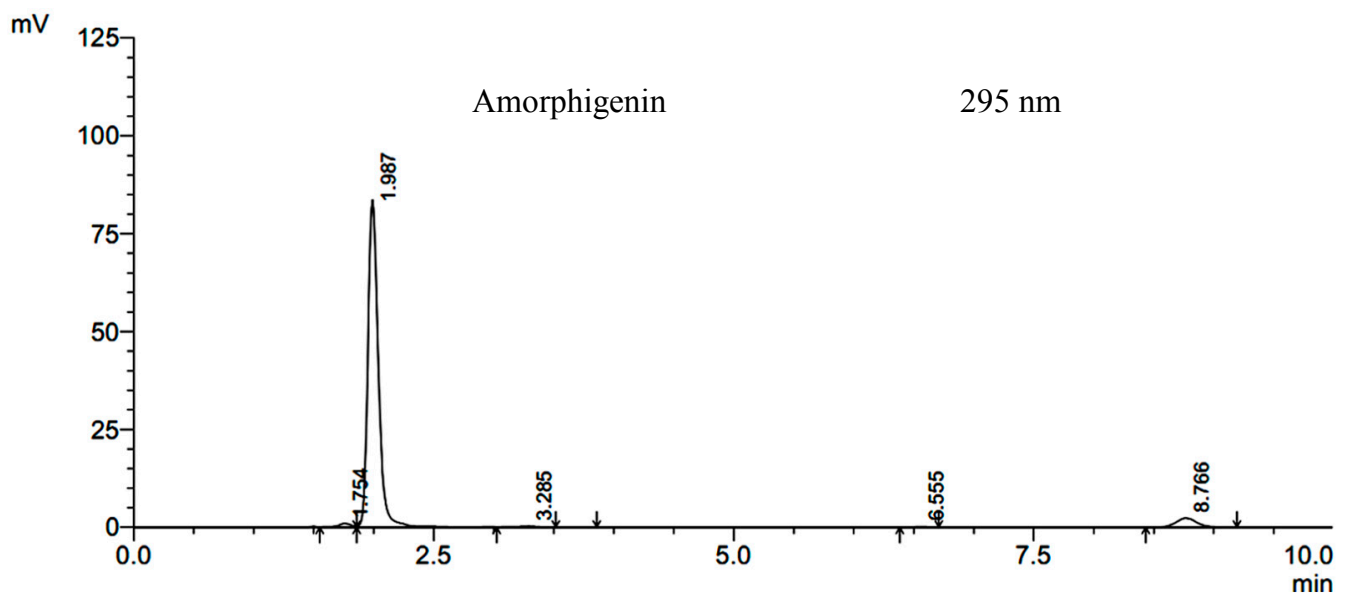

Figure 1. HPLC chromatogram of amorphigenin.

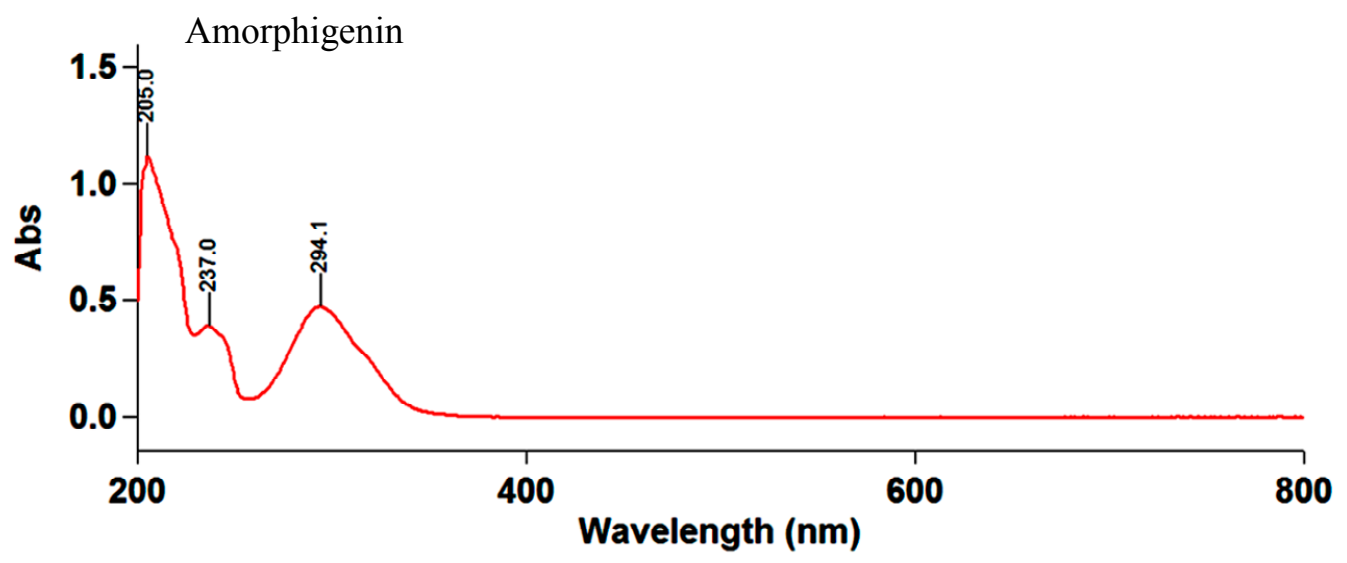

Figure 2. UV spectrum of amorphigenin.

Previous research showed that amorphigenin 8 '- $\beta$-glucoside can cause $85 \%$ mortality of the 4 th instar larvae of $A$. aegypti and termination of pupal formation at $10 \mathrm{mg} / \mathrm{L}$ [52], in the current research, the IR spectra and ${ }^{1} \mathrm{H}-\mathrm{NMR}$ analysis of the bioactive compound indicated that a rotenoid compound, amorphigenin, is one of the main secondary metabolites responsible for larval mortality. Amorphigenin (also known as 8'-hydroxyrotenone), an aglycone of the rotenoid glycoside amorphin [53,54], was 
isolated from the leaves, seeds and seedlings of A. fruticosa $[55,56]$ and shown to have significant anti-proliferative activity [57], anti-cancer activity in many cell types [58,59], hepatoprotective activity [60] and neuraminidase inhibition activity [61]. In our research, the mosquito larvicidal activity of amorphigenin was confirmed, and the $\mathrm{LC}_{50}$ value of $4.29 \mathrm{mg} / \mathrm{L}$ was recorded for early fourth-instar larvae of C. pipiens pallens after $24 \mathrm{~h}$ of exposure, which indicate its highest effect in low dosage.

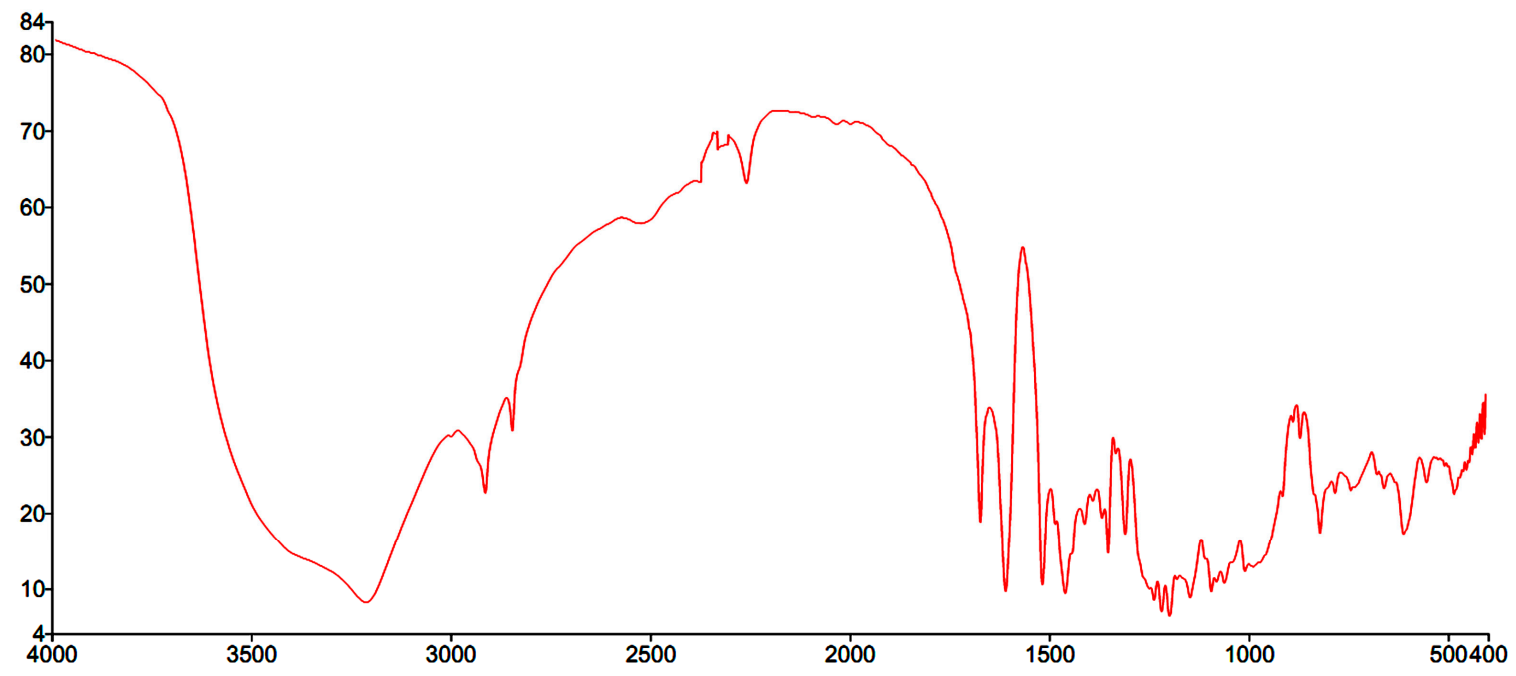

Figure 3. IR spectrum of amorphigenin.

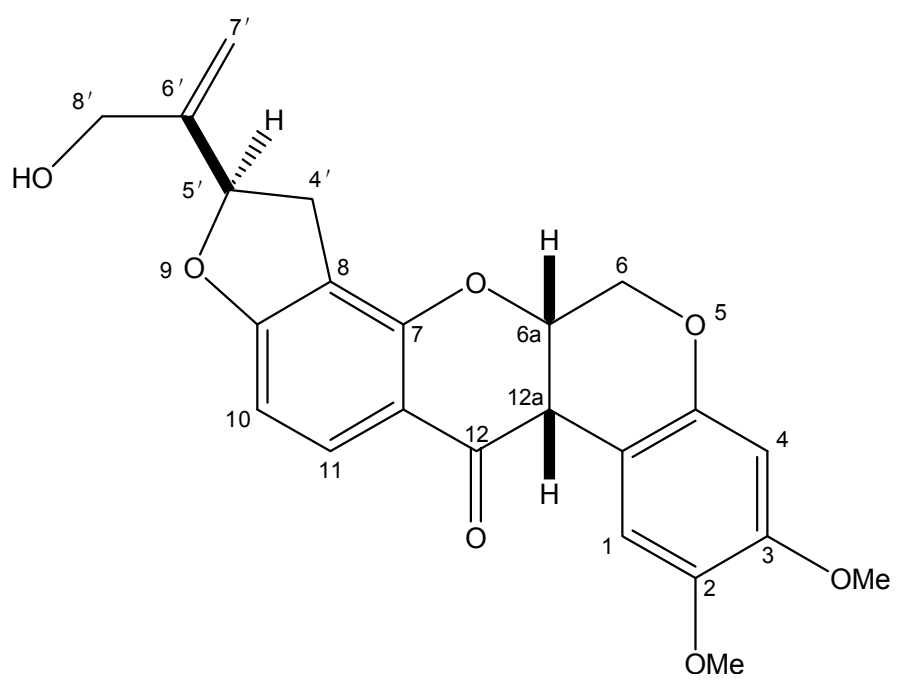

Figure 4. Chemical structure of amorphigenin.

\subsection{Effect of Extracts and Amorphigenin on Larval Mortality}

In the preliminary screening of botanical extracts, all extracts from the seeds of $A$. fruticosa showed moderate larvicidal activities against $C$. pipiens pallens in $24 \mathrm{~h}$ at $150 \mathrm{mg} / \mathrm{L}$ (Table 1), of which the ethanol extract had the most pronounced larvicidal activity, with $94.21 \%$ mortality. The corresponding $\mathrm{LC}_{50}$ values of the petroleum ether, ethyl acetate, chloroform, acetone, and ethanol extracts were $33.02,86.16,36.43,34.23$, and $22.69 \mathrm{mg} / \mathrm{L}$, respectively (Table 2). In other words, the descending order of toxicity is ethanol extract followed by petroleum ether extract, acetone extract, chloroform extract and ethyl acetate extract, the respective, relative potency of these being 1.00, 1.46, 1.51, 1.61 
and 3.80. Further analysis of relative median potency (Table 3) indicates that the LC 50 values show significant differences for the different extracts.

Table 1. Preliminary screening of different solvent extracts of Amorpha fruticosa L. against early fourth instar larvae of Culex pipiens pallens at $150 \mathrm{mg} / \mathrm{L}$.

\begin{tabular}{ccc}
\hline Material & Solvents & \% Mortality ${ }^{\mathbf{a}}(\mathbf{m g} / \mathbf{L}) \pm \mathbf{S E}$ \\
\hline & Petroleum ether & $92.33 \pm 0.1949$ \\
& Ethyl acetate & $69.77 \pm 1.0632$ \\
Seeds of Amorpha fruticosa & Chloroform & $87.89 \pm 0.9112$ \\
& Acetone & $91.26 \pm 0.3515$ \\
& Ethanol & $94.21 \pm 0.2631$ \\
\hline
\end{tabular}

Note: ${ }^{\text {a }}$ Mean value of three replicates.

Table 2. $\mathrm{LC}_{50}$ and $\mathrm{LC}_{90}$ values for the larvicidal activity of extracts and amorphigenin compound from the seeds of $A$. fruticosa against early fourth instar larvae of C. pipiens pallens.

\begin{tabular}{ccccccc}
\hline Treatment & $\mathbf{L C}_{\mathbf{5 0}}(\mathbf{m g} / \mathbf{L})$ & $\begin{array}{c}\text { LCL-UCL } \\
\mathbf{( m g / L )}\end{array}$ & $\mathbf{L C}_{\mathbf{9 0}} \mathbf{( m g / \mathbf { L } )}$ & $\begin{array}{c}\text { LCL-UCL } \\
\mathbf{( m g / L )}\end{array}$ & Regression Equation & R value \\
\hline Petroleum ether & 33.02 & $19.73-55.27$ & 128.45 & $76.74-215.01$ & $\mathrm{Y}=1.7008+2.1723 \mathrm{X}$ & 0.995 \\
Ethyl acetate & 86.16 & $49.78-149.15$ & 339.78 & $196.30-588.15$ & $\mathrm{Y}=0.8375+2.1508 \mathrm{X}$ & 0.995 \\
Chloroform & 36.43 & $25.68-51.67$ & 171.78 & $121.11-243.64$ & $\mathrm{Y}=2.0287+1.9029 \mathrm{X}$ & 0.999 \\
Acetone & 34.23 & $17.18-68.20$ & 138.19 & $69.35-275.38$ & $\mathrm{Y}=1.7558+2.1144 \mathrm{X}$ & 0.992 \\
Ethanol & 22.69 & $11.45-44.96$ & 105.78 & $53.39-209.58$ & $\mathrm{Y}=2.4009+1.9169 \mathrm{X}$ & 0.979 \\
Amorphigenin & 4.29 & $3.22-5.72$ & 11.27 & $8.46-15.01$ & $\mathrm{Y}=3.0665+3.0576 \mathrm{X}$ & 0.993 \\
Rotenone & 4.69 & $3.58-6.15$ & 12.20 & $9.31-15.99$ & $\mathrm{Y}=2.9259+3.0887 \mathrm{X}$ & 0.999 \\
\hline
\end{tabular}

Note: ${ }^{a}$ LCL represents the lower confidence limit, UCL represents the upper confidence limit based on a $95 \%$ Confidence interval.

Table 3. Relative median potency analysis comparing toxicity of different extracts from the seeds of $A$. fruticosa against early fourth instar larvae of $C$. pipiens pallens.

\begin{tabular}{ccccc}
\hline Treatment $^{\mathrm{a}}$ & PE & EAC & MT & DMK \\
\hline EAC & $0.681^{\mathrm{b}}$ & - & - & - \\
MT & 1.018 & 1.538 & - & - \\
DMK & 1.050 & 1.587 & 1.032 & - \\
EA & 1.206 & 1.949 & 1.267 & 1.228 \\
\hline
\end{tabular}

Notes: $\mathrm{PE}=$ Petroleum ether extract from the seeds of $A$. fruticos $a$; EAC $=$ Ethyl acetate extract from the seeds of $A$. fruticosa $; \mathrm{MT}=$ Chloroform. ether extract from the seeds of $A$. fruticos $a$; DMK $=$ Acetone extract from the seeds of $A$. fruticosa; EA = Ethanol extract from the seeds of $A$. fruticosa. ${ }^{\text {a }}$ Comparison between treatment (row vs. column) probit analyses of larvicidal activity. ${ }^{\mathrm{b}}$ Values $<1$ indicate that extract in row is more toxic than extract in column.

Exposure of $C$. pipiens pallens larvae to amorphigenin increased mortality in a concentration-dependent manner. After $24 \mathrm{~h}$ of larval exposure, the $\mathrm{LC}_{50}$ and $\mathrm{LC}_{90}$ values were 4.29 and $11.27 \mathrm{mg} / \mathrm{L}$, respectively (Table 2). Comparing these results to rotenone, which recorded 4.69 and $12.20 \mathrm{mg} / \mathrm{L}$ for $\mathrm{LC}_{50}$ and $\mathrm{LC}_{90}$ values, respectively, against early fourth-instar larvae of C. pipiens 
pallens. However, the statistical analysis showed that significant level value is greater than 0.05 $(\mathrm{sig}=0.064)$, there is no significant difference between amorphigenin and rotenone. The results support the view that the plant $A$. fruticosa harbors potentially bioactive substances against mosquito larvae.

\subsection{Effect of Amorphigenin in Vivo on Inhibition of Mitochondrial Complex I}

Results showed that amorphigenin at $6.26,8.32$ and $10.45 \mu \mathrm{mol} / \mathrm{L}$ decreases mitochondrial complex I activities to $70.33 \%, 67.88 \%$ and $65.73 \%$, respectively, comparable with the control when NADH were used as the substrate (Figure 5). Similarly, rotenone decreases mitochondrial complex I activities to $72.00 \%, 69.85 \%$ and $68.34 \%$, respectively. Mitochondrial complex I (NADH-ubiquinone oxidoreductase, EC 1.6.5.3) catalyzes the transfer of two electrons from NADH to ubiquinone [62]. Inhibition of complex I results in the termination of ATP production. It is believed that rotenone and rotenoids are acting between NADH and coenzyme Q [63]. An in vitro study by Earley et al., showed that amorphigenin and its analog, arylazidoamorphigenin, are potent inhibitors of mitochondrial complex I, comparable to rotenone [64]. With a degree of inhibition similar to that of rotenone, our study shows that amorphigenin is a potent inhibitor against mitochondrial complex I of C. pipiens pallens larvae. The inhibition similarities of mitochondrial complex I can be attributed to similar chemical structures of amorphigenin and rotenone. Spectroscopy research indicates that amorphigenin differs from rotenone in the presence of a hydroxy group in the substituent locus on the E ring [56]. The results suggest that amorphigenin may present the same mode of action as rotenone.

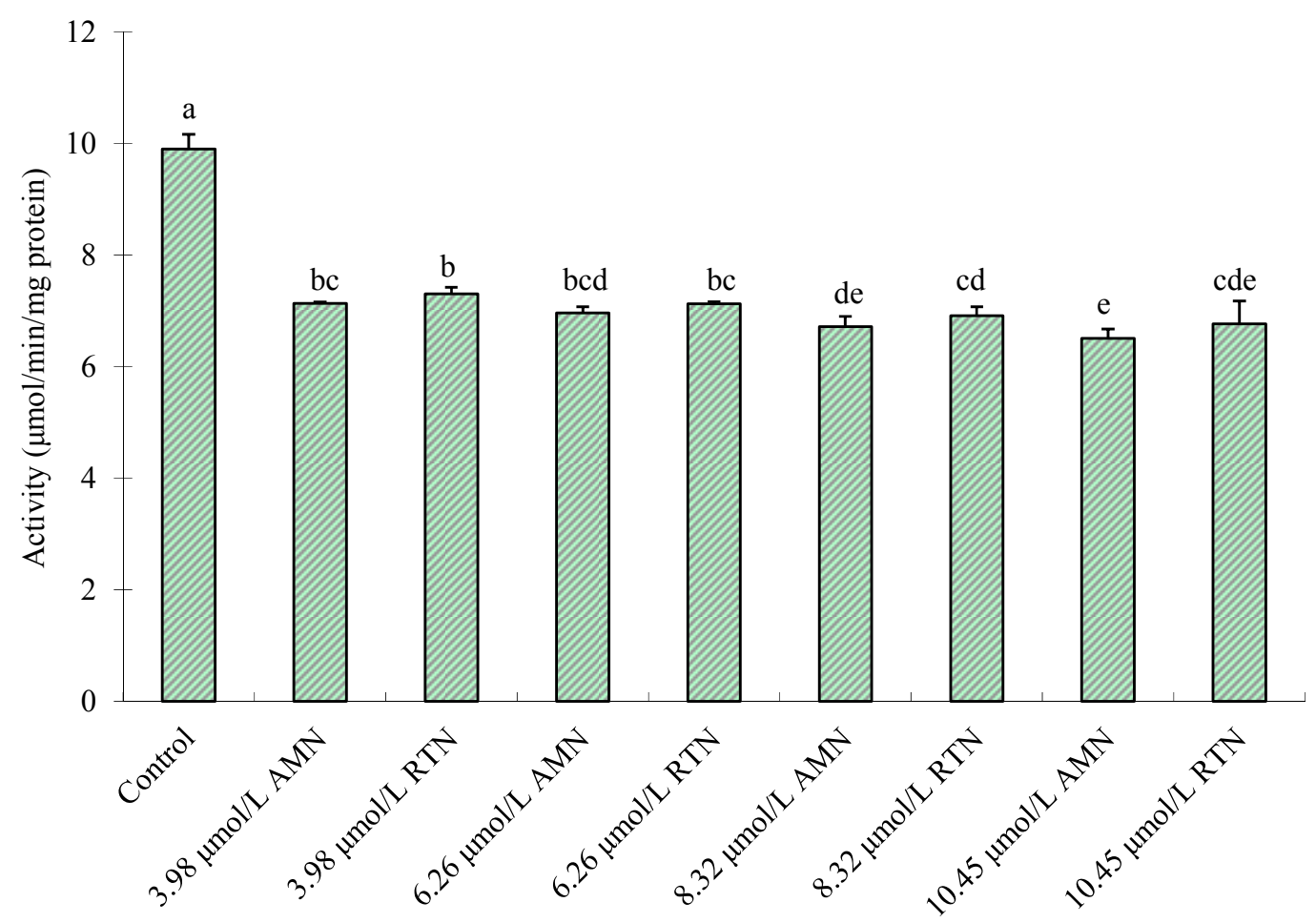

Figure 5. In vivo inhibition of mitochondrial complex I extracted from fourth-instar C. pipiens pallens by three different concentrations of amorphigenin (AMN) and rotenone (RTN) using NADH as substrates. Vertical bars indicate standard errors of the mean $(n=3)$. Different letters on the bars indicate that the means are significant different among the treatments in Fisher's LSD multiple comparison tests $(p<0.05)$. 


\subsection{Effect of Amorphigenin on Protein Production}

Amorphigenin at $6.26,8.32$ and $10.45 \mu \mathrm{mol} / \mathrm{L}$ respectively decreased the protein content by $1.62-$, 1.71-, and 1.98-fold, in comparison with control rates (Figure 6). Rai and Carpinella [65] mentioned that rotenone inhibits the assembly of spindle body canaliculi and the formation of canaliculi of insects in vitro by reversible conjugation with canaliculus protein, changes the components of protein in the integument of Lepidoptera larvae, and decreases the whole protein content. In this research, amorphigenin and rotenone at $10.45 \mu \mathrm{mol} / \mathrm{L}$ decreased the protein content of early fourth-instar larvae of $C$. pipiens pallens by 1.98 - and 1.89 -fold, respectively. In consideration of similarity between chemical structures of amorphigenin and rotenone, amorphigenin may inhibit protein synthesis in the integument and decrease the overall protein content of mosquitoes.

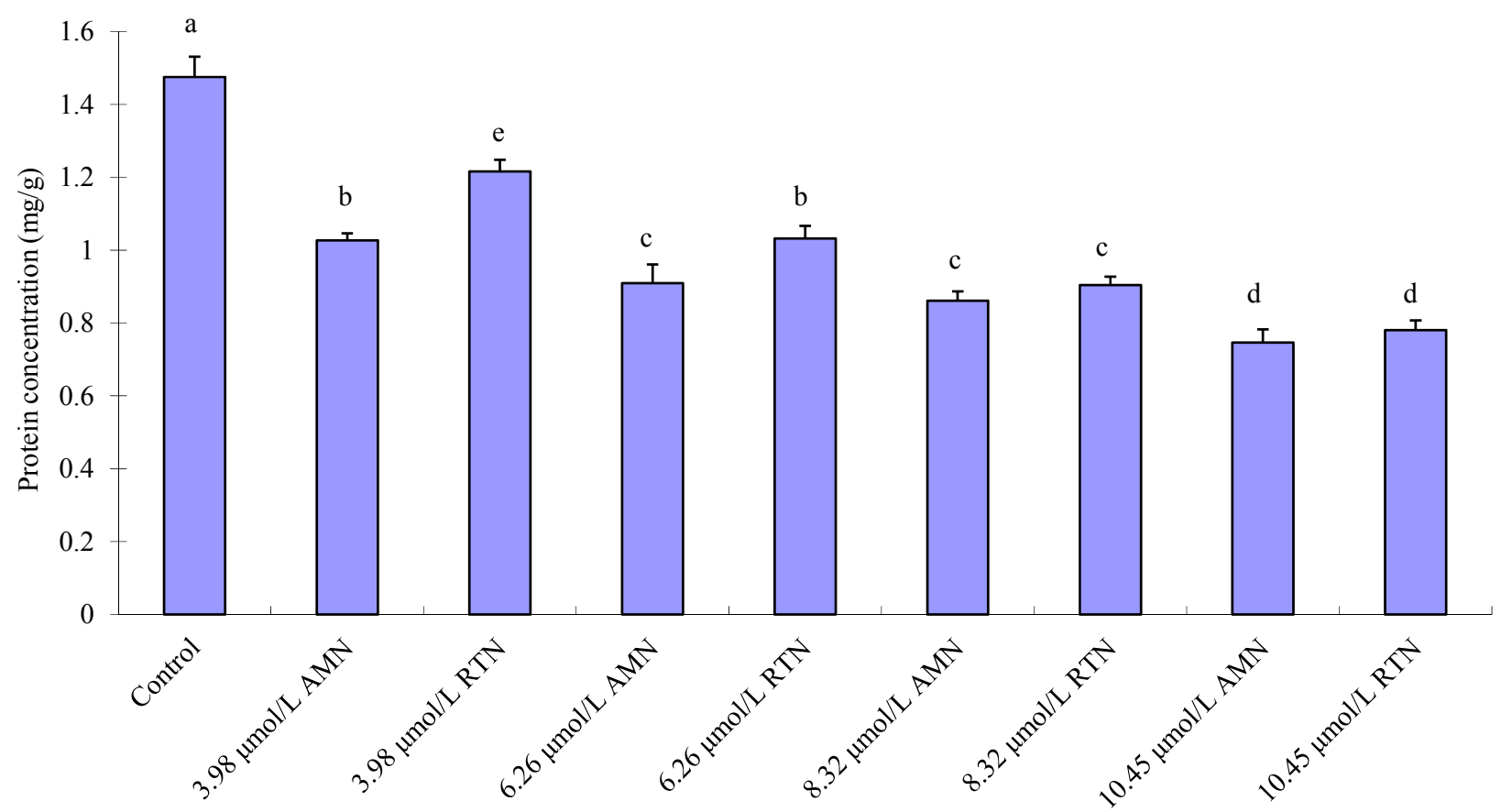

Figure 6. Comparison of total protein concentrations among the control, Amorphigenin $(\mathrm{AMN})$ and Rotenone (RTN) treated fourth-instar larvae of $C$. pipiens pallens following 24-h exposure. Vertical bars indicate standard errors of the mean $(n=3)$. Different letters on the bars indicate that the means are significant different among the treatments in Fisher's LSD multiple comparison tests $(p<0.05)$.

\subsection{Discussion}

Because they demonstrate a wide range of bioactivity and possess contact and fumigant toxicity, plus repellent, oviposition, and feeding deterrence against various mosquito species, several botanicals have been considered as potential mosquito larvae control agents. The use of the plants to control mosquito larvae has been investigated frequently and is well documented by Kishore et al. [66]. Plant secondary metabolites have been increasingly used, given their benefit in mosquito larva control, however, these substances constitute a substantial source of contamination to non-target aquatic organisms that share the same ecological niche as mosquitoes. Moringa oleifera has been used as a 
coagulation reagent for drinking water purification, and can be used as bio-insecticidal tool with potential for the control of insects [67]. However, significant cytotoxic effects were observed from powdered $M$. oleifera seeds at concentrations from 1 to $50 \mathrm{mg} / \mathrm{L}$ [68]. Research by Conti et al. [69] demonstrates that Melaleuca alternifolia essential oil has a remarkable acute toxicity toward the non-target water flea, Daphnia magna, with an LC50 of $80.636 \mathrm{mg} / \mathrm{L}$. The water flea shares the same ecological niche as $A$. albopictus larvae. Thus, non-target effects of natural products against aquatic organisms must be considered in the development of eco-friendly mosquito control strategies. Further research is needed to investigate toxicity of plant secondary metabolite both on target and non-target aquatic arthropods.

\section{Experimental Section}

\subsection{Plant Materials}

In October 2013, the dried seeds of $A$. fruticosa were collected from the campus of Shenyang Agricultural University in Liaoning Province, China (4149'50.10"N, 12333'53.97"E, $41.6 \mathrm{~m}$ altitude), air-dried at room temperature, then ground with an airflow grinder (YF111b, Yongli, Ruian, China). The seeds were authenticated by Associate Professor Guanghui Tang of the College of Forestry, Northwest A\&F University. Voucher specimens have been deposited at The Bio-Pesticide Engineering Research Center of Liaoning Province, Shenyang Agricultural University.

\subsection{Mosquito Culture}

C. pipiens pallens were maintained in our laboratory without exposure to any insecticide at $27 \pm 2{ }^{\circ} \mathrm{C}$ with $75 \%-85 \%$ relative humidity and a $12: 12 \mathrm{~L} / \mathrm{D}$ photoperiod. The larvae of $C$. pipiens pallens were reared in a plastic basin containing a sterilized diet (40 mesh goat liver powder/yeast (2:1) in water). Adult mosquitoes were maintained on a $10 \%$ sucrose solution and blood from a live mouse.

All procedures performed on animals within this study were conducted following guidelines of the Association for Assessment and Accreditation of Laboratory Animal Care International (AAALAC).

\subsection{Preparation of Plant Extracts}

The dried seeds of $A$. fruticosa were finely powdered. Using an ultrasonic processor (KQ-500DE, Kunshan, China), $500 \mathrm{~g}$ of powdered seed was thrice extracted in sequence (60 min per run) by $1500 \mathrm{~mL}$ of petroleum ether organic solvents $\left(60-90{ }^{\circ} \mathrm{C}\right)$, ethyl acetate, chloroform, acetone, and ethanol. The ultrasonic extraction power was set at $350 \mathrm{~W}$ and a frequency of $40 \mathrm{KHz}$. The extract was filtered and concentrated using a rotary vacuum evaporator, and the residue obtained was stored at $4{ }^{\circ} \mathrm{C}$. During preliminary screening, the ethanol extract exhibited the highest larvicidal activity $\left(\mathrm{LC}_{50}=22.69 \mathrm{mg} / \mathrm{L}\right)$ against the early 4 th-instar larvae of $C$. pipiens pallens. Thus the ethanol extract was selected for further isolation and purification by column chromatography and preparative high performance liquid chromatography methods. 


\subsection{Isolation and Purification of Active Ingredients}

The ground seeds of $A$. fruticosa $(1 \mathrm{~kg})$ were extracted three times (three days each time) by ethanol at room temperature. Evaporation of the ethanol yielded a residue (144.88 g), from which a portion $(50 \mathrm{~g})$ was chromatographed on a silica gel column $(9.0 \times 150 \mathrm{~cm})$ using chloroform $/ \mathrm{methanol}$ $(20: 1-3: 1, \mathrm{v} / \mathrm{v})$ as eluant. After analysis by thin-layer chromatography, fractions with similar Rf values were combined to provide seven fractions (I-VII). The larvicidal activities of the fractions I-VII against fourth-instar larvae of $C$. pipiens pallens were tested, wherein fraction I demonstrated strong activity. Next, fraction I (6.87 g) was subjected to serial column chromatography, with varying proportions of benzene and acetone as eluants, to isolate the bioactive fraction, which was then purified by preparative high-performance liquid chromatography. For this process, a Globalsil ODS C18 column was used $(10 \times 250 \mathrm{~mm}, 5 \mu \mathrm{m})$, with methanol/water $(7: 3$, by volume), at a flow rate of $3 \mathrm{~mL} / \mathrm{min}$, and detection at $295 \mathrm{~nm}$. Finally, the potent active rotenoid, amorphigenin was isolated.

The structure of amorphigenin was elucidated mainly by analysis of its NMR spectral data. The melting point was measured on an X-5 melting-point apparatus (Yuhua, Shanghai, China) and is uncorrected. The UV spectrum was obtained on a Cary-50 spectrophotometer (Varian, Palo Alto, CA, USA). The IR spectrum was determined using a PerkinElmer spectrum65 spectrophotometer (Foster City, CA, USA) with potassium bromide pellet. The target compound was isolated and purified on a Shimadzu 2010A HT HPLC apparatus (Kyoto, Japan), equipped with a C18 preparative column $(10 \times 250 \mathrm{~mm}, 5 \mu \mathrm{m})$, with $\mathrm{MeOH} / \mathrm{H}_{2} \mathrm{O}=7: 3$ as eluant and $\mathrm{UV}$ detection at $295 \mathrm{~nm}$. The ${ }^{1} \mathrm{H}-\mathrm{NMR}$ spectrum was recorded on a Bruker-Avance-600 spectrometer (Fällanden, Switzerland), with $\mathrm{CDCl}_{3}$ as solvent and tetramethylsilane (TMS) as internal standard.

\subsection{Larvicidal Bioassay}

The larvicidal activity test was conducted according to the World Health Organization standard protocols [70], with slight modifications. The compound amorphigenin was extracted from seeds of A. fruticosa and rotenone was purchased from Guangxi Shile Agrochemical Co., Ltd (Nanning, China). Briefly, each extract, amorphigenin and rotenone were serially diluted from a stock solution prepared in alcohol. Then, $1 \mathrm{~mL}$ of the serially-diluted extract and compounds were transferred into $200 \mathrm{~mL}$ of distilled water in a $250 \mathrm{~mL}$ sterile glass beaker. The concentrations of the extracts in beaker ranged from $1 \mathrm{mg} / \mathrm{L}$ to $10 \mathrm{mg} / \mathrm{L}$, while the compounds amorphigenin and rotenone in beaker ranged from $10 \mathrm{mg} / \mathrm{L}$ to $100 \mathrm{mg} / \mathrm{L}$. Twenty early fourth-instar larvae of $C$. pipiens pallens were separately introduced into different glass beakers. A separate set of beakers received alcohol only and served as controls. Treated and control larvae were kept under the same conditions used for mosquito maintenance. Mortality rate was recorded at $24 \mathrm{~h}$ after treatment. Dead larvae were identified by failure to move when probed with a needle. The experiments were replicated three times.

\subsection{Assay of Mitochondrial Complex I Activity}

The fourth-instar larvae of $C$. pipiens pallens were exposed to sub-lethal concentrations of amorphigenin and rotenone for $24 \mathrm{~h}$. The sub-lethal concentrations [71,72] ( $\mathrm{LC}_{10}, \mathrm{LC}_{25}, \mathrm{LC}_{40}, \mathrm{LC}_{50}$ at $1.63,2.57,3.41,4.29 \mathrm{mg} / \mathrm{L}$, respectively) of amorphigenin were 3.98, 6.26, 8.32 and $10.45 \mu \mathrm{mol} / \mathrm{L}$. 
The same mole concentration was employed for rotenone. Next, live larvae were collected and isolation of the mitochondria was performed according to Akbar et al. [73]. The Protein concentration of mitochondria was determined by Smith's method [74], using bovine serum albumin (BSA) as standard. Mitochondrial complex I activity of $C$. pipiens pallens was determined as described by Birch-Machin et al. [75] with adaptations for a 96-well format. In brief, $20 \mu \mathrm{L}$ mitochondria and $160 \mu \mathrm{L}$ assay buffer, containing $25 \mathrm{mM}$ phosphate buffer ( $\mathrm{pH}$ 7.2), $5 \mathrm{mM} \mathrm{MgCl}_{2}, 2 \mathrm{mM} \mathrm{NaN}, 2.5 \mathrm{mg} / \mathrm{mL}$ BSA, were added to each well of a 96-well plate, then the microplate was incubated for 20 min at $37{ }^{\circ} \mathrm{C}$ in a microplate reader (Spectramax 190 plate reader, Molecular Devices, Sunnyvale, CA, USA). Finally, the reaction was initiated by the addition of $10 \mu \mathrm{L}$ of $0.13 \mathrm{mM} \mathrm{NADH}$ and measured for 5 min.

\subsection{Protein Assay}

Surviving larvae, collected in bioassay of mitochondrial complex I activity, were homogenized in $0.1 \mathrm{M}$ phosphate buffer ( $\mathrm{pH} 7.0$ ) containing $0.5 \%(\mathrm{v} / \mathrm{v})$ Triton $\mathrm{X}-100$ at the rate of $100 \mu \mathrm{L}$ per larva. After the homogenates were centrifuged at $15,000 \times \mathrm{g}$ for $15 \mathrm{~min}$ at $4{ }^{\circ} \mathrm{C}$, the supernatants were transferred to new tubes for protein determination [76]. The concentration of total protein in each sample preparation was determined based on the method of Smith et al. [74] using bovine serum albumin as standard. Using the microplate reader mentioned above at $562 \mathrm{~nm}$, measurement was performed.

\subsection{Statistical Analysis}

Applying Microsoft Excel 2003 software, the average larval mortality results, adjusted by Abbott [77], were subjected to probit analysis to calculate $\mathrm{LC}_{50}$ and $\mathrm{LC}_{90}$ with their lower and upper confidence limits based on 95\% confidence intervals and correlation coefficient. Significant differences between $\mathrm{LD}_{50}$ values were determined by estimation of confidence intervals of the relative median potency. Two-way analysis of variance (ANOVA) and Fisher's least significant difference (LSD) multiple comparisons were then used to separate the means among the treatments by using the PASW Statistics 18.0 software.

\section{Conclusions}

A considerable number of plant secondary metabolites have proven to be safe and effective against mosquito larvae. However, alternative means of control are being sought due to the dramatic increase in resistance of mosquitoes to chemical insecticides. The present study represents a systematic isolation and identification of bioactive compounds having mosquito larvicidal activity from the seeds of $A$. fruticosa. This study improves knowledge of insecticidal constituents extracted from the seeds of A. fruticosa, and the potent effect of amorphigenin on mitochondrial complex I activity and protein content of $C$. pipiens pallens larvae.

Investigation of larvicidal activity against $C$. pipiens pallens demonstrates that $A$. fruticosa extract has potent insecticidal properties, confirming previous evidence. The insecticidal compound, amorphigenin, exhibits obvious larvicidal activity against $C$. pipiens pallens, and decreases mitochondrial complex I activity as well as protein content of these pests. Our results indicate that amorphigenin is 
strong candidate for a natural, safe and effective phyto-larvicide to be used in population control of C. pipiens pallens.

\section{Supplementary Materials}

Supplementary materials can be accessed at: http://www.mdpi.com/1420-3049/20/02/3238/s1.

\section{Acknowledgments}

The authors would like to acknowledge the anonymous reviewers for their helpful comments and suggestions and Rania A. Abd El-Wahab for reviewing an early version of this manuscript. This work was partially supported by research fund for young teacher from Shenyang agricultural university (No. 20101012), and the National Natural Science Foundation of China (No. 31101675).

\section{Author Contributions}

XL and MJ conceived and designed the research. YL, PQ and ZG performed the experiments and analyzed the data. XL and YL wrote and revised the manuscript. All authors read and approved the final version of the manuscript.

\section{Conflicts of Interest}

The authors declare no conflict of interest.

\section{References}

1. Peng, Z.; Li, H.; Simons, F.E.R. Immunoblot analysis of salivary allergens in 10 mosquito species with worldwide distribution and the human ige responses to these allergens. J. Allergy Clin. Immunol. 1998, 101, 498-505.

2. Li, X.L.; Ma, L.; Sun, L.X.; Zhu, C.L. Biotic characteristics in the deltamethrin-susceptible and resistant strains of Culex pipiens pallens (diptera: Culicidae) in china. Appl. Entomol. Zool. 2002, 37, 305-308.

3. Jiang, S.F.; Zhao, T.Y.; Zhang, Y.M.; Dong, Y.D.; Guo, X.X. RT-PCR detection of west nile virus in mosquitoes and leghorn chicken infected experimentally. Acta Parasitol. Med. Entomol. Sin. 2006, 13, 21-24.

4. Hemingway, J.; Beaty, B.J.; Rowland, M.; Scott, T.W.; Sharp, B.L. The innovative vector control consortium: Improved control of mosquito-borne diseases. Trends Parasitol. 2006, 22, 308-312.

5. Cui, F.; Lin, L.F.; Qiao, C.L.; Xu, Y.; Marquine, M.; Weill, M.; Raymond, M. Insecticide resistance in chinese populations of the Culex pipiens complex through esterase overproduction. Entomol. Exp. Appl. 2006, 120, 211-220.

6. Cui, F.; Raymond, M.; Berthomieu, A.; Alout, H.; Weill, M.; Qiao, C.-L. Recent emergence of insensitive acetylcholinesterase in chinese populations of the mosquito Culex pipiens (diptera: Culicidae). J. Med. Entomol. 2006, 43, 878-883.

7. Cui, F.; Tan, Y.; Qiao, C.-L. Filariasis vector in China: Insecticide resistance and population structure of mosquito Culex pipiens complex. Pest Manag. Sci. 2007, 63, 453-458. 
8. Kim, N.J.; Chang, K.S.; Lee, W.J.; Ahn, Y.J. Monitoring of insecticide resistance in field-collected populations of Culex pipiens pallens (diptera: Culicidae). J. Asia-Pac. Entomol. 2007, 10, 257-261.

9. Shin, E.H.; Kim, N.J.; Kim, H.K.; Park, C.; Lee, D.K.; Ahn, Y.J.; Chang, K.S. Resistance of field-collected populations of Culex pipiens pallens (diptera: Culicidae) to insecticides in the republic of korea. J. Asia-Pac. Entomol. 2012, 15, 1-4.

10. Isman, M.B. Botanical insecticides, deterrents, and repellents in modern agriculture and an increasingly regulated world. Annu. Rev. Entomol. 2006, 51, 45-66.

11. Isman, M.B. Botanical insecticides: For richer, for poorer. Pest Manag. Sci. 2008, 64, 8-11.

12. Benelli, G.; Canale, A.; Conti, B. Eco-friendly control strategies against the asian tiger mosquito, Aedes albopictus (diptera: Culicidae): Repellency and toxic activity of plant essential oils and extracts. Pharmacologyonline 2014, 1, 44-51.

13. Sukumar, K.; Perich, M.J.; Boobar, L.R. Botanical derivatives in mosquito control: A review. J. Am. Mosq. Control Assoc. 1991, 7, 210-237.

14. Shaalan, E.A.-S.; Canyon, D.; Younes, M.W.F.; Abdel-Wahab, H.; Mansour, A.-H. A review of botanical phytochemicals with mosquitocidal potential. Environ. Int. 2005, 31, 1149-1166.

15. Wachira, S.; Omar, S.; Jacob, J.; Wahome, M.; Alborn, H.; Spring, D.; Masiga, D.; Torto, B. Toxicity of six plant extracts and two pyridone alkaloids from Ricinus communis against the malaria vector Anopheles gambiae. Parasites Vectors 2014, 7, 312-320.

16. Dias, C.; Moraes, D. Essential oils and their compounds as Aedes aegypti L. (diptera: Culicidae) larvicides: Review. Parasitol. Res. 2014, 113, 565-592.

17. Han, Y.; Li, L.-C.; Hao, W.-B.; Tang, M.; Wan, S.-Q. Larvicidal activity of lansiumamide b from the seeds of Clausena lansium against Aedes albopictus (diptera: Culicidae). Parasitol. Res. 2013, 112, 511-516.

18. Yang, Y.-C.; Park, I.-K.; Kim, E.-H.; Lee, H.-S.; Ahn, Y.-J. Larvicidal activity of medicinal plant extracts against Aedes aegypti, Ochlerotatus togoi, and Culex pipiens pallens (diptera: Culicidae). J. Asia-Pac. Entomol. 2004, 7, 227-232.

19. Park, I.-K.; Lee, S.-G.; Shin, S.-C.; Park, J.-D.; Ahn, Y.-J. Larvicidal activity of isobutylamides identified in Piper nigrum fruits against three mosquito species. J. Agric. Food Chem. 2002, 50, 1866-1870.

20. Kim, M.-G.; Jeon, J.-H.; Lee, H.-S. Larvicidal activity of the active constituent isolated from Tabebuia avellanedae bark and structurally related derivatives against three mosquito species. J. Agric. Food Chem. 2013, 61, 10741-10745.

21. Park, I.-K.; Shin, S.-C.; Kim, C.-S.; Lee, H.-J.; Choi, W.-S.; Ahn, Y.-J. Larvicidal activity of lignans identified in Phryma leptostachya var. Asiatica roots against three mosquito species. J. Agric. Food Chem. 2005, 53, 969-972.

22. Kim, M.-K.; Jang, Y.-S.; Ahn, Y.-J.; Lee, D.-K.; Lee, H.-S. Larvicidal activity of australian and mexican plant extracts against Aedes aegypti and Culex pipiens pallens (diptera: Culicidae). J. Asia-Pac. Entomol. 2002, 5, 227-231.

23. Wang, Z.; Kim, J.-R.; Wang, M.; Shu, S.; Ahn, Y.-J. Larvicidal activity of Cnidium monnieri fruit coumarins and structurally related compounds against insecticide-susceptible and insecticide-resistant Culex pipiens pallens and Aedes aegypti. Pest Manag. Sci. 2012, 68, 1041-1047. 
24. Jang, Y.S.; Baek, B.R.; Yang, Y.C.; Kim, M.K.; Lee, H.S. Larvicidal activity of leguminous seeds and grains against Aedes aegypti and Culex pipiens pallens. J. Am. Mosq. Control Assoc. 2002, $18,210-213$.

25. Yang, Y.-C.; Lim, M.-Y.; Lee, H.-S. Emodin isolated from Cassia obtusifolia (leguminosae) seed shows larvicidal activity against three mosquito species. J. Agric. Food Chem. 2003, 51, 7629-7631.

26. Benelli, G.; Flamini, G.; Fiore, G.; Cioni, P.; Conti, B. Larvicidal and repellent activity of the essential oil of Coriandrum sativum 1. (apiaceae) fruits against the filariasis vector Aedes albopictus skuse (diptera: Culicidae). Parasitol. Res. 2013, 112, 1155-1161.

27. Conti, B.; Benelli, G.; Flamini, G.; Cioni, P.; Profeti, R.; Ceccarini, L.; Macchia, M.; Canale, A. Larvicidal and repellent activity of Hyptis suaveolens (lamiaceae) essential oil against the mosquito Aedes albopictus skuse (diptera: Culicidae). Parasitol. Res. 2012, 110, 2013-2021.

28. Conti, B.; Leonardi, M.; Pistelli, L.; Profeti, R.; Ouerghemmi, I.; Benelli, G. Larvicidal and repellent activity of essential oils from wild and cultivated Ruta chalepensis 1. (rutaceae) against Aedes albopictus skuse (diptera: Culicidae), an arbovirus vector. Parasitol. Res. 2013, 112, 991-999.

29. Conti, B.; Benelli, G.; Leonardi, M.; Afifi, F.; Cervelli, C.; Profeti, R.; Pistelli, L.; Canale, A. Repellent effect of Salvia dorisiana, S. longifolia, and S. Sclarea (Lamiaceae) essential oils against the mosquito Aedes albopictus skuse (diptera: Culicidae). Parasitol. Res. 2012, 111, 291-299.

30. Benelli, G.; Bedini, S.; Cosci, F.; Toniolo, C.; Conti, B.; Nicoletti, M. Larvicidal and ovideterrent properties of neem oil and fractions against the filariasis vector Aedes albopictus (diptera: Culicidae): A bioactivity survey across production sites. Parasitol. Res. 2015, 114, 227-236.

31. Benelli, G.; Conti, B.; Garreffa, R.; Nicoletti, M. Shedding light on bioactivity of botanical by-products: Neem cake compounds deter oviposition of the arbovirus vector Aedes albopictus (diptera: Culicidae) in the field. Parasitol. Res. 2014, 113, 933-940.

32. Khandagle, A.; Tare, V.; Raut, K.; Morey, R. Bioactivity of essential oils of Zingiber officinalis and Achyranthes aspera against mosquitoes. Parasitol. Res. 2011, 109, 339-343.

33. Cheng, S.-S.; Chang, H.-T.; Chang, S.-T.; Tsai, K.-H.; Chen, W.-J. Bioactivity of selected plant essential oils against the yellow fever mosquito Aedes aegypti larvae. Bioresour. Technol. 2003, 89, 99-102.

34. Abdul Rahuman, A.; Gopalakrishnan, G.; Venkatesan, P.; Geetha, K. Isolation and identification of mosquito larvicidal compound from Abutilon indicum (linn.) sweet. Parasitol. Res. 2008, 102, 981-988.

35. Wedge, D.E.; Klun, J.A.; Tabanca, N.; Demirci, B.; Ozek, T.; Baser, K.H.C.; Liu, Z.; Zhang, S.; Cantrell, C.L.; Zhang, J. Bioactivity-guided fractionation and $\mathrm{gc} / \mathrm{ms}$ fingerprinting of Angelica sinensis and Angelica archangelica root components for antifungal and mosquito deterrent activity. J. Agric. Food Chem. 2008, 57, 464-470.

36. Park, H.-M.; Park, I.-K. Larvicidal activity of Amyris balsamifera, Daucus carota and Pogostemon cablin essential oils and their components against Culex pipiens pallens. J. Asia-Pac. Entomol. 2012, 15, 631-634. 
37. Jang, Y.S.; Jeon, J.H.; Lee, H.S. Mosquito larvicidal activity of active constituent derived from Chamaecyparis obtusa leaves against 3 mosquito species. J. Am. Mosq. Control Assoc. 2005, 21, 400-403.

38. Ma, Z.; Li, Y.; Wu, L.; Zhang, X. Isolation and insecticidal activity of sesquiterpenes alkaloids from Tripterygium wilfordii hook f. Ind. Crops Prod. 2014, 52, 642-648.

39. Xiao, X.-M.; Hu, Z.-N.; Shi, B.-J.; Wei, S.-P.; Wu, W.-J. Larvicidal activity of lignans from Phryma leptostachya 1. Against Culex pipiens pallens. Parasitol. Res. 2012, 110, 1079-1084.

40. Cao, H.-Q.; Yue, Y.-D.; Peng, Z.-H.; Hua, R.-M.; Tang, F. Evaluation of extracts from bamboo for biological activity against Culex pipiens pallens. Insect Sci. 2004, 11, 267-273.

41. Lee, S.E. Mosquito larvicidal activity of pipernonaline, a piperidine alkaloid derived from long pepper, Piper longum. J. Am. Mosq. Control Assoc. 2000, 16, 245-247.

42. Sun, L.; Dong, H.; Guo, C.; Qian, J.; Sun, J.; Ma, L.; Zhu, C. Larvicidal activity of extracts of Ginkgo biloba exocarp for three different strains of Culex pipiens pallens. J. Med. Entomol. 2006, 43, 258-261.

43. Ahn, Y.-J.; Kim, N.-J.; Byun, S.-G.; Cho, J.-E.; Chung, K. Larvicidal activity of Kaempferia galanga rhizome phenylpropanoids towards three mosquito species. Pest Manag. Sci. 2008, 64, 857-862.

44. Perumalsamy, H.; Chang, K.S.; Park, C.; Ahn, Y.-J. Larvicidal activity of Asarum heterotropoides root constituents against insecticide-susceptible and -resistant Culex pipiens pallens and Aedes aegypti and Ochlerotatus togoi. J. Agric. Food Chem. 2010, 58, 10001-10006.

45. Perumalsamy, H.; Kim, J.R.; Kim, S.I.; Kwon, H.W.; Ahn, Y.J. Enhanced toxicity of binary mixtures of larvicidal constituents from Asarum heterotropoides root to Culex pipiens pallens (diptera: Culicidae). J. Med. Entomol. 2012, 49, 107-111.

46. Allen, O.N.; Allen, E.K. The Leguminosae: A Source Book of Characteristics, Uses, and Nodulation; University of Wisconsin Press: Madison, WI, USA, 1981; p. 812.

47. Qu, X.; Diao, Y.; Zhang, Z.; Wang, S.; Jia, Y. Evaluation of anti-bacterial and wound healing activity of the fruits of Amorpha fruticosa L. Afr. J. Tradit. Complement. Altern Med. 2013, 10, 458-468.

48. Brett, C.H. Repellent properties of extract of Amorpha fruticosa. J. Econ. Entomol. 1946, 39, 810-810.

49. Brett, C.H. Insecticidal properties of the indigobush (Amorpha fruticosa). J. Agric. Res. 1946, 73, 81-96.

50. Ji, M.; Liu, C.; Li, X.; Liu, D.; Wu, D.; Wang, Y. Insecticidal and antifeeding activity of seeds of Amorpha fruticosa against Schizaphis graminum. Jiangsu Agric. Sci. 2011, 39, 208-210.

51. Sariaslani, F.S.; Rosazza, J.P. Microbial transformations of natural antitumor agents: Products of rotenone and dihydrorotenone transformation by Cunninghamella blakesleeana. Appl. Environ. Microbiol. 1983, 45, 616-621.

52. Abe, F.; Donnelly, D.M.X.; Moretti, C.; Polonsky, J. Isoflavanoid constituents from Dalbergia monetaria. Phytochemistry 1985, 24, 1071-1076.

53. Kondratenko, E.S.; Kasymov, A.U.; Abubakirov, N.K. Structure of amorphigenin. Chem. Nat. Compd. 1967, 3, 260-262. 
54. Kasymov, A.U.; Kondratenko, E.S.; Abubakirov, N.K. Stepwise hydrolysis of amorphin. Chem. Nat. Compd. 1970, 6, 482-482.

55. Crombie, L.; Dewick, P.M.; Whiting, D.A. Biosynthesis of rotenoids. Chalcone, isoflavone, and rotenoid stages in the formation of amorphigenin by Amorpha fruticosa seedlings. J. Chem. Soc. Perkin Trans. 1 1973, 1285-1294, doi:10.1039/P19730001285.

56. Kadyrova, F.R.; Shamsutdinov, M.R.I.; Shakirov, T.T. The isolation of fruticin from the seeds of Amorpha fruticosa. Chem. Nat. Compd. 1973, 9, 107-107.

57. Li, L.; Wang, H.K.; Chang, J.J.; McPhail, A.T.; McPhail, D.R.; Terada, H.; Konoshima, T.; Kokumai, M.; Kozuka, M.; Estes, J.R.; et al. Antitumor agents, 138. Rotenoids and isoflavones as cytotoxic constitutents from Amorpha fruticosa. J. Nat. Prod. 1993, 56, 690-698.

58. Konoshima, T.; Terada, H.; Kokumai, M.; Kozuka, M.; Tokuda, H.; Estes, J.R.; Li, L.; Wang, H.K.; Lee, K.H. Studies on inhibitors of skin tumor promotion, xii. Rotenoids from Amorpha fruticosa. J. Nat. Prod. 1993, 56, 843-848.

59. Kim, B.G.; Kwak, H.B.; Choi, E.Y.; Kim, H.S.; Kim, M.H.; Kim, S.H.; Choi, M.K.; Chun, C.H.; Oh, J.; Kim, J.J. Amorphigenin inhibits osteoclast differentiation by suppressing c-fos and nuclear factor of activated t cells. Anat. Cell Biol. 2010, 43, 310-316.

60. Kloutek, E.; Popov, A.; Drenska, D.; Uzunov, P. Experimental research on the hepatoprotective activity of flavonoids isolated from Amorpha fructiosa. Eksp. Med. Morfol. 1985, 24, 50-54.

61. Kim, Y.S.; Ryu, Y.B.; Curtis-Long, M.J.; Yuk, H.J.; Cho, J.K.; Kim, J.Y.; Kim, K.D.; Lee, W.S.; Park, K.H. Flavanones and rotenoids from the roots of Amorpha fruticosa L. That inhibit bacterial neuraminidase. Food Chem. Toxicol. 2011, 49, 1849-1856.

62. Darrouzet, E.; Issartel, J.-P.; Lunardi, J.; Dupuis, A. The 49-kda subunit of NADH-ubiquinone oxidoreductase (complex I) is involved in the binding of piericidin and rotenone, two quinone-related inhibitors. FEBS Lett. 1998, 431, 34-38.

63. Hollingworth, R.M.; Ahammadsahib, K.I.; Gadelhak, G.; McLaughlin, J.L. New inhibitors of complex I of the mitochondrial electron transport chain with activity as pesticides. Biochem. Soc. Trans. 1994, 22, 230-233.

64. Earley, F.G.; Ragan, C.I. Photoaffinity labelling of mitochondrial NADH dehydrogenase with arylazidoamorphigenin, an analogue of rotenone. Biochem. J. 1984, 224, 525-534.

65. Rai, M.; Carpinella, M.C. Pesticides based on plant essential oils: from traditional practice to commercialization. In Naturally Occurring Bioactive Compounds; Elsevier Science Ltd: Amsterdam, The Netherlands, 2006; p. 178.

66. Kishore, N.; Mishra, B.; Tiwari, V.; Tripathi, V.; Lall, N. Natural products as leads to potential mosquitocides. Phytochem. Rev. 2014, 13, 587-627.

67. De Oliveira, C.F.R.; Luz, L.A.; Paiva, P.M.G.; Coelho, L.C.B.B.; Marangoni, S.; Macedo, M.L.R. Evaluation of seed coagulant Moringa oleifera Lectin (cmol) as a bioinsecticidal tool with potential for the control of insects. Process Biochem. 2011, 46, 498-504.

68. Al-Anizi, A.A.; Hellyer, M.T.; Zhang, D. Toxicity assessment and modelling of Moringa oleifera seeds in water purification by whole cell bioreporter. Water Res. 2014, 56, 77-87.

69. Conti, B.; Flamini, G.; Cioni, P.; Ceccarini, L.; Macchia, M.; Benelli, G. Mosquitocidal essential oils: Are they safe against non-target aquatic organisms? Parasitol. Res. 2014, 113, 251-259. 
70. World Health Organization. Instructions for Determining the Susceptibility or Resistance of Mosquito Larvae to Insecticides; WHO/VBC/81.807, Ed.; WHO: Geneva, Switzerland, 1981.

71. Mahmoudvand, M.; Abbasipour, H.; Garjan, A.; Bandani, A. Sublethal effects of indoxacarb on the diamondback moth, Plutella xylostella (L.) (lepidoptera: Yponomeutidae). Appl. Entomol. Zool. 2011, 46, 75-80.

72. Piri, F.; SAhrAGArd, A.; GhAdAMyAri, M. Sublethal effects of spinosad on some biochemical and biological parameters of Glyphodes pyloalis walker (lepidoptera: Pyralidae). Plant Prot. Sci. 2014, 50, 135-144.

73. Akbar, S.M.; Sharma, H.C.; Jayalakshmi, S.K.; Sreeramulu, K. Methylparathion- and carbofuran-induced mitochondrial dysfunction and oxidative stress in Helicoverpa armigera (noctuidae: Lepidoptera). Pestic. Biochem. Physiol. 2012, 103, 31-37.

74. Smith, P.K.; Krohn, R.I.; Hermanson, G.T.; Mallia, A.K.; Gartner, F.H.; Provenzano, M.D.; Fujimoto, E.K.; Goeke, N.M.; Olson, B.J.; Klenk, D.C. Measurement of protein using bicinchoninic acid. Anal. Biochem. 1985, 150, 76-85.

75. Birch-Machin, M.A.; Briggs, H.L.; Saborido, A.A.; Bindoff, L.A.; Turnbull, D.M. An evaluation of the measurement of the activities of complexes I-IV in the respiratory chain of human skeletal muscle mitochondria. Biochem. Med. Metab. Biol. 1994, 51, 35-42.

76. Jin-Clark, Y.; Anderson, T.; Zhu, K. Effect of alachlor and metolachlor on toxicity of chlorpyrifos and major detoxification enzymes in the aquatic midge, Chironomus tentans (diptera: Chironomidae). Arch. Environ. Contam. Toxicol. 2008, 54, 645-652.

77. Abbott, W.S. A method of computing the effectiveness of an insecticide. J. Econ. Entomol. 1925, $18,265-267$.

Sample Availability: Samples of the compounds amorphigenin are available from the authors.

(C) 2015 by the authors; licensee MDPI, Basel, Switzerland. This article is an open access article distributed under the terms and conditions of the Creative Commons Attribution license (http://creativecommons.org/licenses/by/4.0/). 